\title{
El alcoholismo en las Antillas Holandesas. Resultados de un modelo de intervención
}

\author{
Amaro González, G. *; Grullón Espinal, M.A.** \\ * Médico psiquiatra. Departamento de Salubridad e Higiene. Bonaire. Antillas Holandesas. \\ * Médico psiquiatra. Clínica Psiquiátrica Dr. David R. Capriles. Curazao. Antillas Holandesas.
}

\section{RESUMEN}

Los autores describen sus resultados en el tratamiento de 21 pacientes con dependencia alcohólica primaria, residentes en Curazao y Bonaire (Antillas Holandesas), atendidos con un esquema terapeútico conformado por Internamiento durante 28 días, utilización del cinedebate terapeútico para la realización de psicoterapia individual, de pareja y de familia, clorhidrato de flufenazina (Prozac), lorazepam (Ativán), vitaminoterapia, e incorporación a un grupo de Alcohólicos Anónimos de Curazao, con el que los autores mantienen comunicación directa por su lider, que también integró la el grupo tratado. El período estudiado estuvo comprendido entre el 02 de Agosto de 1997 y el 30 de Abril de 1998.

Un año seguimiento después del egreso, 18 pacientes $(90.4 \%)$ se encuentran en fase de remisión total sostenida (según el DSM-IV) a pesar de tratarse de pacientes con historia de varios años de dependencia, recaídas e importantes afecciones somáticas evidentemente relacionadas con el consumo del alcohol. Se concluye que el tratamiento utilizado, toma en cuenta los aspectos biosociales del enfermo, y resulta de fácil organización y manejo confiable.

Palabras clave: Dependencia alcohólica. Tratamiento biosocial. Cinedebate terapeútico. Fluoxetina

\section{INTRODUCCIÓN}

$\mathbf{L}$ a significación económica y social del alcoholismo está implícita en los problemas de salud, laborales y espirituales que determina (1). EI consumo irresponsable del alcohol en los Estados Unidos de América, determina gastos sociales anuales ascendentes a 100.000 millones de dólares, cifra que representa el $50 \%$ de los daños económicos ocasionados por todas las drogas disponibles en ese país (2). Estas realidades estadísticas, potencialmente generalizables al mundo desarrollado, llevan a evaluar constantemente la efectividad de los recursos biosociales utilizados en el tratamiento de esta dro-

\section{SUMMARY}

The authors describe the results of the treatment of 21 patients residing in Curazao and Bonaire (Netherlands Antilles). These patients suffered from alcohol dependency and were treated in acordance to the following shceme: hospitalization during 28 days, use of therapeutic movie debates for individual, partner, and family psychotherapy, fluoxetin clorhidrate (Prozac), lorazepam (Ativan), vitamin therapy and incorporation into one of the Alcoholic Anonimous groups in Curazao, with which the authors have good contact by one of its leaders, who in turn was one of the 21 patients undergoing treatment. The treatment took place between August 01, 1997, and April 30,1998 . In the group size studied, 18 patients are in sustained full remission (acoording to the DSM-IV) 12 months after discharged resulting in a $90.4 \%$ of therapeutic success, in spite of the patients having multiple years of dependency, relapses, and important somatic illnesses evidently related to alcohol consumption. The authors conclude that the treatment scheme takes into consideration the patients biosocial aspects and is furthermore easy to organize and manage.

Key words. Alcohol dependency. Biosocial treatment. Therapeutic movie debate. Fluoxetine.

gadicción modelo (3), estableciéndose a veces, absurdos enfrentamientos entre procedimientos que en lugar de antagonizarse, se complementan.

La situación en las Antillas Holandesas es similar, en sentido general, a la existente en América Latina y el área del Caribe, resultando el alcoholismo motivo frecuente de atención ambulatoria e institucional.

Motivados por lo antes expuesto decidimos estudiar nuestra casuística privada, con el propósito de evaluar el resultado del esquema terapeútico que utilizamos, integrado por recursos que considerados por separado, han generado criterios disímiles que van desde su aceptación total, hasta su rechazo absoluto. 


\section{OBJETIVOS}

\section{Generales}

Describir algunas características sociodemográficas y clínicas de los integrantes de una muestra de dependientes alcohólicos primarios, y delimitar su respuesta al esquema terapeútico utilizado.

\section{Especificos}

Establecer en el grupo estudiado:

1 Los antecedentes familiares mas cercanos, de alcoholismo

2. Los problemas de mayor significación psicosocial vinculados por los pacientes a su alcoholismo.

3. Los trastornos somáticos constatados antes del tratamiento.

4. Las principales manifestaciones somáticas y Psíquicas detectadas durante la primera semana de hospitalización

5. La proporción de pacientes sin recaídas durante un año de seguimiento.

\section{PACIENTESY MÉTODO}

La muestra quedó integrada por 21 pacientes con dependencia alcohólica primaria sin otras afecciones precedentes vinculadas patogénicamente con el alcoholismo y disgnosticados según criterios del DSMIV(4).

La selección se produjo por orden sucesivo de llegada a nuestra consulta privada durante el período comprendido entre el 1 de Agosto de 19997 y el 30 de Abril de 1998, y la vía de remisión fué en el 38\% el departamento de control de disciplina laboral de los trabajadores de Antillas Holandesas y en el $62 \%$ el médico de familia responsable de su atención.

Sistemática de trabajo.

1. Realización de dos entrevistas en las que se valoró el caso, se estableció la alianza terapeútica y se decidió-previo acuerdo con el paciente-el internamiento en una de las dos clínicas no gubernamentales de Curazao, donde los autores realizan su práctica privada.

El criterio de exclusión fue la existencia de manifestaciones psicopatológicas que no hicieran factible el manejo del paciente en estas instituciones no psiquiátricas.

2. Internamiento continuo, durante 28 días, con el propósito de estudio integral y garantizar la abstinencia total de alcohol.
3. Valoración por parte el internista y realización de los siguientes estudios: hemograma, urea, glicemia, amilasa pancreática, ácido úrico, pruebas funcionales hepáticas, ultrasonido hepático, H.I.V., E.C.G., rayos X de tórax, En dos casos se solicitó atención por el neurólogo y este indicó resonancia magnética nuclear y E.E.G.

4. Utilización de clorhidrato de fluoxetina (Prozac) $20 \mathrm{mg}$ en dosis oral matutina desde el ingreso hasta el corte evolutivo un año despues del egreso.

5. Utilización diaria de thiamine 100 mg intramuscular por 15 días.

6. Utilización de lorazepam (Ativán) dosis máxima oral diaria de $6 \mathrm{mg}$ en tres tomas durante los 15 primeros días, y reducción progresiva hasta supresión total antes del egreso.

7. Biblioterapia mediante la recomendación de materiales específicos algunos de cuyos fragmentos se discuten simultáneamente con las sesiones de cinedebate para reforzar con los mismos las imágenes más significativas. Entre estos materiales se encuentran obras de alta difusión internacional como "No seas co-dependiente, de Melody Beattie (5), y "Diálogo y ayuda con alcohólicos y otros toxicómanos de Ricardo González (6).

8. Realización, durante el período de internamiento de al menos cuatro sesiones de psicoterapia individual, una de psicoterapia de familia y una de psicoterapia de pareja con la utilización del cinedebate como recurso básico.

La psicoterapia que utilizamos es de proyección ecléctica e incluye recursos de orientación cognitivo conductual (7), dinámica (8), didactica, inspirativa, persuasiva, sugestiva, sistémica y existencial (9).

El recurso central en nuestra psicoterapia es el cinedebate, método creado por Acosta Nodal, psiquiatra cubano de alta experiencia quién lo maneja con proyecciones cinematográficas y discusiones en grupo al final de las mismas (10). Nosotros incluímos variantes como el uso del video y sobre todo, detención y discusión de imágenes movilizadoras, con lo que hemos obtenido relevantes abreaciones. Entre los filmes mas frecuentemente utilizados hay algunos de tipo comercial (11), otros elaborados con propósitos específicos e incluímos siempre dos orientados al abordaje del binomio depresión-suicidio (12)(13).

El programa psicoterapeútico garantiza la discusión de los siguientes tópicos: riesgos del consumo de alcohol, progresión de la dependencia, solución de conflictos, conducta asertiva y pasivo agresiva, negación, situaciones familiares relacionadas con el alcoholismo, co-dependencia, metas futuras, manejo de la agresividad, manejo del stress, identificación de pérdidas y valores, importancia de la asistencia a los grupos de A.A., estilo de vida, prevención de recaídas, autoestima, la comunicación del paciente con los 
demás, y otras situaciones especificas de cada caso. La duración de las sesiones fluctúa entre una y dos y media horas.

9. Seguimiento luego del egreso, mediante sesiones al menos mensuales y con la utilización del cinedebate y entrevistas cara a cara.

10. Incorporación a los grupos de A.A. con la exigencia controlada de al menos una sesión semanal.

Los idiomas empleados son el español y el inglés.

\section{RESULTADOS}

Las características fundamentales de la muestra fueron:

18 hombres y 3 mujeres; $46 \%$ con edades comprendidas entre 47 y 52 años y edad pro medio global de 45,3 años al momento del ingreso; 17 nacidos en Curazao-Bonaire, 2 holandeses, 1 húngaro y I norteamericano; 76,2 \% eran casados o acompañados; $95,2 \%$ con escolaridades superiores a secundaria; $61,9 \%$ comerciantes por cuenta propia; todos fueron de procedencia urbana; y el tiempo promedio de consumo excesivo fue de 14 años.

En el cuadro 1 se aprecia la elevada proporción de pacientes que reportaron familiares alcohólicos en el primer grado de consanguinidad sobresaliendo los padres con 61,9\%.La repercusión psicosocial fundamental de su alcoholismo en la apreciacion de los pacientes fue: Violencia familiar 42,9\%; arrestos policíacos 28,6; sanciones laborales $19 \%$ y pérdida de vínculo laboral 9,5.

Los trastornos somáticos constatados antes del tratamiento se exponen en el cuadro 2 donde la hipercolesterolemia se recogió en el $66 \%$ de los pacientes; las hepatopatías en el 47,6\%; y las polineuropatias en el $42,9 \%$, datos que nos permiten inferir el grado de severidad del alcoholismo en nuestra muestra.

El cuadro 3 recoge los signos y síntomas evidenciados durante la primera semana de hospitalización, donde los temblores, la taquicardia, y las diarreas resultaron los mas frecuentes entre los primeros y la tristeza, insomnio, e ideas suicidas entre los segundos.

\begin{tabular}{|lcc|}
\hline \multicolumn{4}{|c|}{ CUADRO 1} \\
\multicolumn{2}{|c|}{$\begin{array}{c}\text { Distribución de la muestra según familiar } \\
\text { alcohólico con mayor vínculo consanguineo }\end{array}$} \\
\hline Familiar alcohólico & $\mathbf{N}^{\mathbf{o}}$ de casos & Porciento \\
\hline Padre & 13 & 61.9 \\
Madre & 1 & 4.8 \\
Hermano & 2 & 9.6 \\
Abuelo & 1 & 4.8 \\
Tío & 1 & 4.8 \\
Primo & 3 & 14.1 \\
Totales & 21 & 100 \\
\hline
\end{tabular}

\section{CUADRO 2}

Distribución de la muestra según trastornos somáticos constatados antes del tratamiento.

\begin{tabular}{|c|c|c|}
\hline Trastorno & Número de pacientes ${ }^{\circ}$ & Porciento \\
\hline Hipercolesterolemia & 14 & 66.6 \\
\hline Hígado graso, alteraciones en pruebas funcionales & 10 & 47.6 \\
\hline Polineuropatía & 9 & 42.9 \\
\hline Desnutrición & 6 & 28.6 \\
\hline Pancreatitis crónica & 4 & 19.0 \\
\hline Infarto antiguo del miocardio & 1 & 4.8 \\
\hline Hernia discal ${ }^{\circ}$ & 1 & 4.8 \\
\hline
\end{tabular}

\section{CUADRO 3}

Distribución de la muestra según signos y síntomas detectados en la primera semana

\begin{tabular}{lcclrr}
\hline Signos & Número $^{\mathbf{0 0}}$ & $\mathbf{\%}$ & Síntomas & Número & $\%$ \\
\hline Temblores & 12 & 57.1 & Tristeza & 11 & 52.4 \\
Taquicardia & 10 & 45.2 & Insomnio & 5 & 23.8 \\
Diarreas & 4 & 19.0 & Ideas suicidas & 3 & 14.3 \\
Sudoración intensa & 2 & 9.5 & Hipobulia & 3 & 14.3 \\
\hline
\end{tabular}

๑ Posibilidad de manifestaciones múltiples 
Finalmente, 2 hombres y 1 mujer (14,2\%), con edad promedio de 49,6 años, recayeron durante la etapa de seguimiento, específicamente en los 4 primeros meses después del egreso.

\section{DISCUSIÓNY CONCLUSIONES}

Como observaciones de proyecciónes crosculturales, destacaremos la alta proporción de pacientes con parejas estables $(72,6 \%)$, pese a la severidad y duración del alcoholismo, así como el mantenimiento del vínculo laboral de los 6 pacientes con empleos gubernamentales pese a su larga historia de consumo excesivo, situación que podría interpretarse como indicador de cierta actitud social de tolerancia, frecuente en la cultura caribeña.

También resulta destacable la elevada proporción de alcoholismo en los padres, y dos características igualmente observables en Cuba y República Dominicana: la muy baja frecuencia de cuadros de delirum tremens agudos o subagudos y el reducido porcentaje de cirrosis hepáticas, aún en bebedores de larga data.

La utilización prolongada del clorhidrato de fluxetina (Prozac) que resultó perfectamente tolerado, persiguió efectos antidepresivos, y sobre todo la atenuación del craving (14)(15).

El lorazepam (Ativán), se indicó para el control de los síntomas de abstinencia y elevar el umbral convulsivo. Se tomó en cuenta también su metabolización por vía de la glucuronización, mecanismo que se mantiene aún cuando exista daño hepático (16).

La cifra de 18 pacientes $(90,4 \%)$ con remisión total sostenida — según criterios del DSM. IV—durante un año después del egreso, realmente superó nuestras expectativas, dada la severidad de los cuadros tratados y su resistencia a tratamientos anteriores. En los 3 pacientes que recayeron se habían evidenciado actitudes egosintónicas ante el alcohol, su ingreso ocurrió por presiones familiares, y se desvincularon de A.A. en los dos pri meros meses del egreso.

Como conclusión, el esquema terapeútico utilizado determinó resultados satisfactorios y en nuestro criterio, sus pilares básicos fueron el cinedebate, la asistencia a grupos de A.A. y la fluoxetina.

\section{REFERENCIAS BIBLIOGRÁFICAS}

1. Amaro, G.; González, R.; García, L. “Comportamiento sexual del paciente alcohólico y su pareja" Revista Española de Drogodependencias.1997. 22(2), 135-140.

2. González, R. "Clínica Psiquiátrica Básica Actual" Editorial Científico Técnica. La Habana. 1998,

3. González, R..."El Alcoholismo y su Atención Específica. Editorial Ciencias Médicas. La Habana 1994.

4. Asociación Psiquiátrica Americana."Manual de Diagnóstico y Estadístico de los Trastornos Mentales. Editorial Masson S.A. Barcelona 1995.

5. Beattie, M." No seas co—dependiente" $3^{\text {ra }}$ Edición. Editorial Atlántida. Bogotá, 1994.

6. González R." Diálogo y Ayuda en el Tratamiento de Alcohólicos y otros Toxicómanos. Editorial Artes Gráficas, Univalle. Cali. 1997.

7. Colina, L.; Behrens, S." Terapia Cognitiva" $3^{\text {ra }}$ Edición. Editorial Metrópolis, Caracas. 1990.

8. Diaz, I." Técnica de la Entrevista Psicodinámica" Editorial Pax. México D.F. 1990.

9. González, R. "Psicoterapia de Alcohólicos y otros Toxicómanos" Editorial Científico Técnica. La Habana 1996.

10. Acosta, C. "Cinedebate Terapeútico"Rev. Del Hosp. Psiq. de la Hab.1989, 30 (4) 295-610.

11. Kerner, J.; Avnet, J. Producers, and Mandoki, L. Direcrtor. “When a Man Loves a Woman."Film. U.S.A. 1994.

12. Eli Lilly and Company. Producer. Depression: The Road to Recovery.Film.U.S.A. 1992.

13. Eli Lilly and Company. Producer. and National Mental Health Association. Moving Back to The Light.Film.U.S.A- 1993.

14. American Psychiatric Aassociation. "Practice Guideline for the Treatment of Patients, with Substance Use Disorders: Alcohol, Cocaine and Opioids. American Journal of Psychiatry 1995,152(1)30-39.

15. Huertas, D. Fluoxetine in Severe Alcohol Dependence.Disertation in The American Psychiatric Association, Annual Meeting. Toronto.Canada Proceeding. 1999.

16. Hyman, S.; Arana, G.; Rosenbaum, J.; Handbook of Psychiatric Therapy, Third Edition, Little Brown and Company. New York.. 1995. 